\title{
Bacharelado em Turismo no Brasil: História e contribuições da Universidade Federal do Paraná
}

\author{
Tourism Bachelor's Degree in Brazil: \\ History and Paraná Federal University's contributions
}

\author{
Daniela Sousa Nunes Oganauskas (OGANAUSKAS, D. S. N.) \\ Bruno Martins Augusto Gomes (GOMES, B. M. A.) ${ }^{* *}$ \\ Alcimara Meira Gonçalves Andrukiu (ANDRUKIU, A. M. G.) ${ }^{* * *}$
}

\begin{abstract}
RESUMO - As universidades têm como fundamento a construção e disseminação do conhecimento para a sociedade, formando profissionais e cidadãos nas diferentes áreas do saber. Nesta realidade a Universidade Federal do Paraná (UFPR, Curitiba, Brasil) se destaca na área do turismo, visto que o seu curso de bacharelado em turismo é um dos pioneiros do Brasil. Assim, diante da importância histórica da UFPR para o bacharelado em turismo no país, a pesquisa sócio-histórica sobre este curso possibilita uma contribuição para a história do ensino de graduação em turismo no Brasil. Dessa maneira, esta pesquisa teve por objetivo realizar uma investigação sócio-histórica sobre o curso de bacharelado em turismo da UFPR. Para tanto foi elaborado um marco teórico abordando o histórico do ensino de graduação em Turismo no Brasil bem como seus desafios e perspectivas. Na sequência os dados foram coletados por meio de pesquisa documental e as entrevistas foram verificadas pela análise de conteúdo. Como resultado observa-se que o curso de bacharelado em turismo da UFPR passou por diversas transformações em sua estrutura, especialmente na matriz curricular. Sua contribuição se faz presente por meio de centenas de egressos, diversos projetos vinculados à sociedade e pesquisas as quais geram novos conhecimentos na área do turismo. Assim, a partir de uma percepção atenta ao mercado, crítica em relação à realidade sociocultural, visando uma formação integral, o curso alcança o seu reconhecimento.
\end{abstract}

Palavras-chave: Bacharelado em Turismo; UFPR; Atuação Profissional.

ABSTRACT - Universities are founded on the construction and dissemination of knowledge to society, graduating professionals and citizens in different areas of knowledge. In this reality, Paraná Federal University (UPFR) stands out in the field of tourism, since his bachelor degree in tourism is one of the pioneers of the country. Thus, given the historical importance of UFPR for the bachelor's degree in tourism in Brazil, the socio-historical research of this course provides a contribution to the history of undergraduate education in tourism in Brazil. Thus, this research aimed to conduct a socio-historical research on the bachelor degree in tourism in Paraná Federal University. For that goal it was elaborated a theoretical framework approaching of the history of graduation in Tourism in Brazil as well as its challenges and prospects. In the sequence, the data were collected through documental research and the interviews were analyzed by content analysis. As a result it is observed that the bachelor degree in tourism of UFPR has gone through by several transformations in its structure, especially in the curriculum. Its contribution is present through hundreds of graduated people, many projects related to research and society which generating new knowledge in the tourism area. Thus, from a market attentive perception, critical in relation to sociocultural reality, aiming at a whole formation, the course reaches its recognition.

Keywords: Tourism Bachelor's Degree; UFPR; Professional Performance

\footnotetext{
* Graduação em Turismo (Bacharelado) pela Universidade Federal do Paraná (UFPR). Mestranda em Políticas Públicas na UFPR. Endereço para correspondência: Rua Professor Rodolfo Belz, 790, bl. 01, ap. 21. CEP: 82640-570 - Curitiba - PR (Brasil). Telefone: 41 3779-5294. E-mail: dsn.daniela@gmail.com

** Graduação em Turismo (Bacharelado) pela Universidade Federal de Ouro Preto (UFOP). Mestrado em Administração pela Universidade Federal de Lavras (UFLA). Doutorando em Políticas Públicas na UFPR. Professor do Departamento de Turismo da UFPR. Endereço para correspondência: Rua Dr. Faivre, 405. CEP: 80060-140 - Curitiba - PR (Brasil). Telefone: 41 3360-5050. Email: gomesbma@ufpr.br

*** Graduação em Administração (Bacharelado) pela Faculdade Estadual de Filosofia, Ciências e Letras de Paranaguá. Graduanda em Turismo na UFPR. Servidora Técnico-Administrativo da UFPR. Endereço para correspondência: Rua Jaguariaíva, 512. CEP: 83260-970 - Matinhos - PR (Brasil). Telefone: 41 8414-8614. E-mail: alcimarameira@gmail.com
} 


\section{INTRODUÇÃO ${ }^{1}$}

As universidades são espaços fundamentais na sociedade para a construção do conhecimento. Estas se destacam como possibilidade para o fortalecimento de estudos e discussões de assuntos relevantes em diferentes áreas. Nesta realidade se destaca a Universidade Federal do Paraná (UFPR), que há aproximadamente um século desponta por meio de conhecimentos construídos junto à comunidade, que alcançam resultados locais e globais. Dentre os seus campos de atuação está o turismo, área em que é referência. Cabe destacar que os primeiros anos que o turismo se fez presente no meio acadêmico do Brasil coincidem com a criação desta área de ensino, pesquisa e extensão na UFPR.

Assim, surgiu a seguinte indagação: quais os aspectos históricos que marcaram o curso de bacharelado em Turismo ao longo da história da Universidade Federal do Paraná? Visando responder às indagações apresentadas, esta pesquisa teve por objetivo realizar uma investigação socio-histórica sobre o curso de bacharelado em Turismo da UFPR. Mais especificamente, a pesquisa buscou levantar aspectos históricos que envolveram o curso de bacharelado em Turismo da UFPR ressaltando as contribuições do curso para a sociedade e para a formação profissional nesta área do conhecimento.

Diante da importância histórica da UFPR para o bacharelado em Turismo no Brasil, a pesquisa socio-histórica deste curso se justifica, pois possibilita uma contribuição para a própria história do ensino de graduação em turismo no país. As informações aqui apresentadas são decorrentes de levantamento bibliográfico; análise documental e análise de conteúdo de entrevistas realizadas com atores envolvidos diretamente com o desenvolvimento do curso.

É importante ressaltar que a contextualização acerca do ensino de turismo no Brasil e sobre a atuação profissional na área, apresentadas no artigo, visam situar mais especificamente a realidade na qual se insere o curso da UFPR. Da mesma forma este trabalho não tem por finalidade esgotar toda a história do referido curso. Assim, o texto divide-se em cinco partes. Inicialmente é discutida a história do ensino de turismo no

\footnotetext{
1 A versão preliminar deste artigo foi apresentada no evento V Congresso Latino-Americano de Investigação Turística, realizado na cidade de São Paulo (São Paulo, Brasil) nos dias 3 a 5 de setembro de 2012 .
} 
Brasil. Em seguida abordam-se as relações do ensino com a prática de turismo no século XXI assim como a metodologia adotada nesta pesquisa. Oriundos desta fundamentação são expostos os resultados da pesquisa os quais tratam da história do curso de bacharelado em Turismo da UFPR e suas principais contribuições. A partir de então são apresentadas as considerações finais.

\section{O ENSINO DE TURISMO NO BRASIL}

As universidades surgiram na Europa na Idade Média. Na América Latina, enquanto a Espanha permitia a criação de universidades em suas colônias, no século XIX, no Brasil era predominante o encaminhamento dos brasileiros a Portugal e França para a obtenção de diploma universitário (ARANHA, 2006).

Assim, no Brasil, apesar da existência de algumas escolas superiores no século $\mathrm{XIX}$, as primeiras universidades surgiram somente no século XX. De acordo com Martins (2002), até a proclamação da república em 1889, o ensino superior desenvolveu-se muito lentamente, com faculdades que ofereciam um diploma profissional com direito a ocupar postos privilegiados em um mercado de trabalho restrito além de garantir prestígio social. Como em toda a América Latina, estas se constituíam em espaços para promover os valores da modernidade e da racionalidade baseados em moldes europeus.

Neste cenário se destaca a Universidade Federal do Paraná. Fundada em 1912 se consolidou como referência no estado do Paraná bem como no ensino superior do Brasil. Os primeiros cursos ofertados foram Ciências Jurídicas e Sociais, Engenharia, Medicina e Cirurgia, Comércio, Odontologia, Farmácia e Obstetrícia (UFPR, 2011). Segundo a mesma fonte, assim como outras universidades, ao longo de sua história a UFPR proporcionou à comunidade não apenas ensino, mas também pesquisa e extensão universitária. Dessa maneira, as universidades, enquanto núcleos de excelência na construção do conhecimento se consolidaram ao articularem estas três áreas (ensino, pesquisa e extensão) influenciando e sendo influenciadas pelo ambiente em que estão inseridas. 
Acompanhando o desenvolvimento político, cultural e social deste ambiente, as instituições de ensino superior no Brasil a partir do final da década de 1960 começaram a despertar para o ensino do turismo, conforme evidencia o histórico apresentado por Matias (2005). Ainda, segundo a autora em 1966 o Decreto-lei nº 55/66 definiu a Política Nacional de Turismo e criou a EMBRATUR - Empresa Brasileira de Turismo (atual Instituto Brasileiro de Turismo) e em 1971, o parecer do Conselho Federal de Educação - CFE no. 35/71 criou o curso superior de Turismo, sendo estabelecido no mesmo ano o currículo mínimo e a duração do curso de Turismo.

De acordo com a autora, na época da criação da EMBRATUR, em 1966, pouco destaque era dado à atividade turística, e muito menos para o ensino dela. A grande iniciativa para uma ampliação da atenção sobre a profissionalização em turismo se deu a partir do momento que a mão de obra para este setor começou a ser requisitada. Matias (2005) comenta que o primeiro curso superior de Turismo surgiu na Universidade Anhembi Morumbi em 1971 e a partir de então surgiram inúmeros outros cursos de bacharelado, pós-graduação e tecnológicos dedicados ao turismo nas décadas posteriores. Prossegue afirmando que seguindo esta tendência, ainda na primeira metade da década de 1970, a Universidade de São Paulo e as universidades católicas do Rio Grande do Sul, de Campinas e de Pernambuco também criaram seus cursos de turismo. Diante da relevância da atividade para o país, a UFPR, em 1978, instalou o seu curso de Turismo, sendo um dos primeiros entre as universidades federais do país. (MATIAS, 2005).

Ao longo destas décadas o interesse político e mercadológico pelo turismo expandiu-se assim como a academia progrediu na construção do conhecimento relacionado à área. Entendendo o turismo enquanto um sistema, o qual envolve aspectos culturais, sociais, ecológicos e econômicos em busca da sustentabilidade (BENI, 2001), é necessário reconhecer a permanente incompletude no seu processo de investigação teórico. Assim, conforme expõe Moesh (2002), se configura um desafio para os sujeitos implicados na concepção de sustentabilidade prática e teórica da atividade.

A estrutura curricular dos cursos de Turismo no Brasil é marcada por diversas propostas desde a década de 1970, existindo desde esta época duas polaridades relevantes ligadas ao enfoque mercadológico e ao enfoque teórico, mais direcionado para a pesquisa. 
Matias (2008, p. 65) ao analisar estas estruturas curriculares entende que um curso de Turismo seja composto pelas:

\begin{abstract}
Disciplinas de Formação Básica: Filosofia, Ética, Antropologia, Informática, Comunicação e Expressão, Sociologia, Psicologia Aplicada ao Turismo, Métodos e Técnicas de Pesquisa em Turismo, Estatística, Sistemas de Informação, Direito e Legislação Turística, Políticas Públicas de Turismo, Geografia, História Geral e Brasil, Introdução à Administração, Língua Estrangeira, Economia, Matemática e Contabilidade.

Disciplinas de Formação Específica: Fundamentos do Turismo ou Introdução ao Turismo, Mercado Turístico ou Sistema de Turismo, Agência de Turismo, Sistema de Transportes, Planejamento e Organização Turístico, Métodos de Planejamento (Inventários), Meios de Hospedagem. Educação Ambiental, Lazer e Recreação, Relações Públicas, Planejamento e Organização de Eventos, Cerimonial, Alimentos e Bebidas, Elaboração e Análises de Projetos, Marketing Turístico.

Disciplinas de Formação Complementar: Técnica Publicitária, Recursos Humanos, Ecoturismo, Legislação Ambiental, Museologia, Arqueologia. Estudos teóricos-práticos realizados em espaços de fluxo turístico possibilitando aliar teoria e prática, podendo compreender visitas técnicas, inventário turístico, laboratórios de aprendizagem e de estágios.
\end{abstract}

Em relação ao corpo docente Moraes (2008) coloca que apenas no início do século XXI o número de bacharéis em turismo titulados alcançou o necessário para que as instituições de ensino superior tivessem um quantitativo suficiente de professores mestres e doutores. De acordo com a autora, entre as décadas de 1970 e 1990 os estímulos para que os docentes da área continuassem seus estudos foi pequeno, sendo que até o final do século XX havia poucos programas de pós-graduação stricto-sensu na área do turismo. Outra questão levantada por Moraes (2008) em relação ao corpo docente de turismo está relacionada à carga horária, visto que a maior parte das contratações dos professores ocorre na categoria horista. Contudo, nas universidades públicas nos últimos anos esta situação está mais adequada, visto a predominância de mestres e doutores, muitos com regime de trabalho de dedicação exclusiva.

$\mathrm{Na}$ visão de um turismo mais científico, reforçam-se as atividades acadêmicas e de produção intelectual, ao passo que em relação à aproximação com o mercado há uma busca por demandas mais técnicas. Tomazoni (2007) destaca que o ambiente acadêmico e o cotidiano de trabalho são modelos paralelos, mas que muitas vezes não estão bem conectados. Para o autor é necessária a elaboração de um modelo de qualificação (interdisciplinar) que deve aliar teoria/prática da mesma forma que o saber/fazer deve estar direcionado para dar respostas às demandas do mercado. Portanto, Tomazoni 
(2007) dá ênfase para a capacidade de empregabilidade que a cadeia produtiva de turismo proporciona discutindo assim os desafios vinculados a promoção de uma educação adequada a cada um dos postos de trabalho que podem ser ocupados.

Ao contrário de Tomazoni, Moesch (2002) reforça o contexto no qual se colocam as discussões sobre a epistemologia do turismo. Para ela, o turismo enquanto um fenômeno marcadamente multissetorial em sua produção e interdisciplinar em sua teoria, precisa ser encarado epistemologicamente dentro desta abrangência. Ela coloca que da mesma maneira que as práticas de turismo se modificam na pós-modernidade também precisam se modificar as interpretações e conduções da atividade turística enquanto condução do pensamento. A autora apresenta, portanto, uma nova perspectiva de observação na qual o mercado e as evoluções sociais, econômicas (multissetoriais) embasam a pesquisa e a condução do pensamento sobre turismo ao longo do tempo.

Assim, para Nechar (2007) o turismo, considerado uma atividade econômica internacional pela movimentação econômica e tecnológica, acaba por ser segmentado em relação à produção de conhecimentos. De um lado tem-se educação, treinamento e capacitação profissional focada no atendimento às necessidades do mercado, e de outro se tem a educação acadêmica focada em trabalhar o turismo enquanto fenômeno social, promovendo a compreensão de sua essência.

\section{O TURISMO E A ATUAÇÃO PROFISSIONAL NO SÉCULO XXI}

Para Tomazoni (2007) o turismo é uma atividade que possui uma ampla cadeia produtiva e muitas possibilidades de segmentação, mas que acaba sofrendo com uma fragilidade em termos de oferta de emprego. Apesar de carecer de profissionais capacitados para atender as demandas de prestação de serviços, o turismo é uma das áreas que pouco valoriza sua mão de obra.

Conforme colocam Sogayar e Rejowski (2011), o setor possui uma diversidade de produtos e serviços, todavia, ofertados em grande parte por pequenos empreendimentos, conduzidos por empresários sem formação específica atinente, de maneira que frequentemente é desconsiderada a necessidade do profissionalismo na área. Existe, portanto, uma separação entre o crescimento do turismo enquanto atividade 
que depende de mão de obra qualificada, e o fato de esta mão de obra ainda não possuir a valorização e a remuneração adequada. O estudo de Medaglia e Silveira (2010) esclarece a atuação profissional do turismólogo ao evidenciar, mediante uma análise em Curitiba (Paraná, Brasil), que o aumento da remuneração deste profissional está vinculado ao tempo de formado e ao nível de formação, ocorrendo uma concentração da mão de obra na iniciativa privada e não predominando a atuação no exterior após graduar-se.

Diante deste cenário, é relevante a colocação de Beni (2002) ao destacar que os profissionais de turismo precisam ser empreendedores de si mesmos, agregando conhecimentos, trabalhando com inteligência e estando atualizados em relação às diferentes tecnologias que são apresentadas atualmente. $\mathrm{O}$ autor afirma ainda que além destes passos importantes para alcançar um espaço no mercado de trabalho é necessário um entendimento sistêmico da atividade que contemple: meio ambiente, aspectos sociais do turismo, análise econômica, patrimônio cultural, segmentação do mercado, hospitalidade, transportes turísticos, administração e organização de eventos, comunicação na sociedade globalizada, política do turismo, planejamento estratégico, bem como, de estar voltado para o desenvolvimento sustentável do turismo.

Nesta dimensão da complexidade que envolve o turismo, além de observar os elementos descritos por Beni, tem-se em Schlüter (2002) a ênfase no desafio de observar os resultados econômicos do turismo por ser uma atividade que movimenta a economia em várias pontas da ampla cadeia produtiva. Já em relação à avaliação social, ela ressalta o cenário de ampliação da renda, como também o impacto que os turistas geram no cotidiano das comunidades, tanto na incorporação de uma capacitação específica para o atendimento ao turismo, como na interferência cultural que o turista gera na comunidade.

Além destes desafios, Panosso Netto et al. (2011) destacam a necessidade da construção de uma teoria consistente para o turismo pautada em conhecimento filosófico, contemplando os estudos em diferentes idiomas e que possa ser aplicada em diferentes realidades, para que assim se possibilite àqueles que se dedicam a trabalhar pelo turismo uma ação pautada na visão crítica.

Desta forma estas especificidades do turismo se refletem no ensino por meio de conteúdos, temas e atividades visando aproximar os futuros profissionais da realidade 
em que atuarão. Há uma busca por deixar claro ao longo da formação a complexidade da atividade turística. Todavia, como esta realidade é dinâmica, os profissionais de turismo, desde a graduação, devem buscar por caminhos que lhes permitam compatibilizar o que é transmitido no meio acadêmico, com as suas habilidades individuais e as exigências profissionais.

\section{METODOLOGIA}

Seguindo as orientações de Creswell (2007) este trabalho se estrutura na caracterização e resposta a algumas questões de pesquisa. Considerando estas questões e buscando atender seus objetivos, esta pesquisa se configura como qualitativa. Nesta, como afirma Triviños (1987), após uma interpretação dos fenômenos num contexto, os resultados são expressos em formas narrativas, ilustradas com declarações das pessoas dando fundamento à investigação. Seguindo as perspectivas da pesquisa qualitativa, é necessário caracterizar a abordagem utilizada, cabendo neste caso uma utilização da abordagem sócio-histórica. Freitas (2002, p. 7) enfatiza que:

\footnotetext{
Nessa abordagem a compreensão dos fenômenos a partir de seu acontecer histórico no qual o particular é considerado uma instância da totalidade social. A pesquisa é vista como uma relação entre sujeitos, portanto dialógica, na qual o pesquisador é uma parte integrante do processo investigativo.
}

$\mathrm{Na}$ coleta de dados foram utilizadas entrevistas e pesquisa documental, sendo utilizados registros públicos da Universidade como base preliminar do processo. Seguindo as proposições de Alencar (2007) relacionadas à entrevista, foi utilizado um roteiro de entrevista de acordo com o problema de pesquisa, o objetivo do estudo e o referencial teórico. Este instrumento de coleta de dados teve por base observar atores que fizeram parte da história do bacharelado em Turismo da Universidade Federal do Paraná. Entre os anos de 2010 e 2011 foram entrevistados professores que atuam ou atuaram no curso (alguns ligados à fase inicial do curso), uma secretária assim como alunos egressos do curso de bacharelado em Turismo, com aprovação de divulgação dos relatos por todos os entrevistados. A seleção dos documentos assim como dos 
entrevistados foi realizada considerando a disponibilidade dos mesmos e as limitações de tempo dos pesquisadores.

As informações qualitativas adquiridas ao longo das pesquisas foram interpretadas por meio da análise de conteúdo, conceituada por Bardin (1977) como um conjunto de técnicas de análise das comunicações que permite a inferência de conhecimentos relativos às condições de produção/recepção destas mensagens. A operacionalização da análise de conteúdo deve possuir uma sequência de procedimentos que inclui a pré-análise, a codificação, a categorização e a inferência a partir das respostas.

Finalmente, cabe destacar que a análise de dados tem como influência as percepções do pesquisador. Esta se dá na medida em que ele também pondera a relação dos dados coletados e os contextos nos quais foram observados, o que caracteriza as bases da pesquisa qualitativa.

\section{BACHARELADO EM TURISMO DA UFPR: ASPECTOS HISTÓRICOS E RELAÇÕES COM A SOCIEDADE}

De acordo com a professora Deanna Farah a criação do curso de turismo na UFPR teve seus trâmites legais iniciados no ano de 1976, no Setor de Ciências Humanas, Letras e Artes, por incentivo da então diretora Professora Cecília Maria Westphalen. A entrevistada acrescentou que por meio de uma comissão de professores e profissionais, designados pela Prof ${ }^{a}$. Cecília, foi aberto o Processo $\mathrm{n}^{\circ} 110029 / 76$, para a criação do curso de Turismo da UFPR, que foi aprovado, primeiro pelo Conselho de Ensino e Pesquisa, em 12/04/1977 e, em seguida, pelo Conselho Universitário, em 2 de maio de 1977. Assim, em 1978, foi aberta a primeira turma de turismo desta universidade.

Dessa maneira, a história do curso de bacharelado em turismo da UFPR tem como referência a professora Deanna Farah, a qual coordenou o curso de Turismo durante os anos de 1979 a 1991, e foi professora de várias disciplinas. Esta ao fazer uma breve descrição dos desafios enfrentados nos seus primeiros anos destacou, dentre outros, a dificuldade de encontrar estágios para os alunos do curso, bem como a necessidade de constantes adequações curriculares: 
Bom, esse curso era considerado uma ameaça para as pessoas que trabalhavam em agências [...] quando chegou a época de estágios [...] a gente teve muita dificuldade pra isso, nós tivemos principalmente estágios na Paranatur [Empresa Paranaense de Turismo] [...] foram algumas dificuldades que a gente foi tendo [...] mudanças de currículos também e readequação, [...] enquanto eu estive lá nós mudamos o currículo duas vezes [...].

A professora Deise Maria Fernandes Bezerra, aluna da primeira turma do curso, acrescenta que:

[...] comecei a fazer o curso, então fiz 78, 79 e 80 e a minha formatura foi em 81 [...]. E na realidade [...] eu peguei todo o início do curso, se hoje tem problemas [...] então imagine como era aquele tempo, que não tinha muitas agências, que não tinha muitos lugares para fazer estágio, mas assim, [...] eu julgo, que o curso de turismo, ele conseguiu, desde a minha que foi a primeira turma, despertar bastante a vontade de realmente a gente mudar aquilo que tava acontecendo no turismo, [...] então eu acho que foi um início e eu acho que a Federal deu uma contribuição muito grande.

Um dos aspectos destacados pelos entrevistados, diz respeito à disponibilidade $\mathrm{e}$ ingresso de docentes com formação específica em turismo, aspecto que se manteve ainda por muito tempo. Em 1991, ano de ingresso da entrevistada Irene Camilo no curso e sua atual secretária, este contava somente com dois professores graduados em turismo:

[...] eu fiz o vestibular para o curso de turismo em 90, entrei no curso em 91 [...] a questão dos professores, eu tive mais professores de outras áreas, tive professor de administração, de literatura, de relações públicas [...] e poucos de Turismo, de turismo só tinha o professor Eduardo Pereira e o professor Miguel [...].

A professora Farah, destacou que somente em 1985 é que houve o primeiro concurso para professores do Curso de Turismo. Neste foram abertas inscrições para professores específicos da área de turismo, o que possibilitou a entrada, já como professor concursado, dentre 11 candidatos, do egresso do curso, o Professor Miguel Bahl. Ele que foi o primeiro de muitos outros que o seguiram. Durante esta fase inicial, tanto o espaço físico quanto o acadêmico eram compartilhados com outros cursos, como o de Ciências Sociais e o de Comunicação, aglutinados em um único departamento, o Departamento de Comunicação e Ciências Sociais - DECOMCISO e posteriormente os cursos de Comunicação Social e de Turismo junto ao Departamento de Comunicação Social e Turismo - DECOMTUR. A entrevistada acrescenta que: 


\begin{abstract}
O Departamento de Ciências Sociais - DECISO - Contava com número ideal de professores, o que não acontecia com o Departamento de Comunicação Social, motivo de junção dos dois departamentos com o nome de DECOMCISO. Aos poucos o Departamento de Comunicação Social foi acrescentando mais professores em seu quadro e no final de 1985 o departamento já possuía número suficiente de docentes para desligar-se do DECOMCISO e novamente se tornarem dois departamentos. Em 1986, o Departamento de Comunicação passa a funcionar no prédio central com o nome de DECOMTUR - Departamento de Comunicação Social e Turismo (Arquivos da Coordenação do Curso de Turismo/UFPR).
\end{abstract}

No ano 2000, o curso já se encontrava dissociado do Departamento de Comunicação Social e Turismo (DECOMTUR), funcionando isoladamente como Departamento de Turismo (DETUR) que teve como sede inicial a sala do programa de extensão universitária AGETUR - local em que os professores se organizavam para preparar suas atividades. Por sua vez, surgia também o Departamento de Comunicação - DECOM aglutinando apenas o Curso de Comunicação Social.

Os primeiros dirigentes eleitos do DETUR foram os professores: Miguel Bahl e Luciane de Fátima Neri - como chefe e suplente, respectivamente - e neste mesmo ano os professores Laura Alice Rinaldi Camargo e Eduardo Manoel Marques Pereira como coordenadora e vice do Curso de Turismo, respectivamente.

As condições não eram das melhores. E isso é peculiar à história do Curso de Turismo, a qual é marcada por sucessivas conquistas e superações. Tal afirmativa é sustentada pelos diversos trechos encontrados nas atas das reuniões ordinárias e extraordinárias do DETUR, como por exemplo:

O professor Miguel Bahl informou que o transtorno causado pela separação de móveis e equipamentos entre DECOM e DETUR será uma fase transitória e que em breve tais dificuldades serão sanadas, pois já está tomando as providencias cabíveis em pleitear junto a esta Instituição a reposição de móveis e equipamentos (UFPR, 2001a).

Era um período de adaptação, até mesmo frágil em relação à motivação dos professores e percepção dos alunos quanto ao rumo que tomaria toda aquela movimentação causada pela separação dos departamentos. Na ata de 13 de março de 2001, o professor Miguel Bahl relatou sobre a adequação do espaço físico e que fizeram um estudo sobre este, mas a UFPR não dispunha de arquiteto para elaborar um projeto (UFPR, 2001b). 
Além dessa solicitação, prosseguiram-se pedidos de suprimento material e de funcionários, como segue:

O prof. Miguel informou que foram enviados ofícios ao Pró-Reitor de Administração solicitando móveis, equipamentos e carteiras escolares, e oficio ao de Recursos Humanos e Assuntos Estudantis solicitando técnicos administrativos. [...] o Banco do Brasil doou uma mesa para reuniões e seis cadeiras com rodízio (UFPR, 2001b).

$\mathrm{Na}$ ata do dia 5 de abril de 2001, é relatado que o espaço físico, até então ocupado somente pelo DETUR ( $2^{\circ}$ andar do Prédio Histórico na Praça Santos Andrade/Travessa Alfredo Bufren), estava sendo cogitado para uso exclusivo do curso de Psicologia em função de que o curso de Turismo poderia ser transferido para o prédio Dom Pedro II (Campus Reitoria) onde funcionava anteriormente o Setor de Sociais Aplicadas (UFPR, 2001c). Além destes desafios encontrados na disposição de espaço físico e de recursos humanos, o DETUR enfrentou alguns obstáculos na composição de seu corpo docente, como encontrado no trecho da ata 19/2001, de 23/10/2001:

\begin{abstract}
O Prof. Miguel Bahl apresentou a situação precária do Departamento para a continuidade de ensino, para o curso de Turismo, pois o DETUR possui cinco vagas abertas e sem reposição de professores efetivos. [...] das cinco vagas, apenas duas estão preenchidas com professores substitutos. [...] Tal situação acarreta sobrecarga didática aos demais professores do Departamento, e sérias dificuldades de continuidade didática sem a realização de processos seletivos para Professor Substituto para as demais vagas (UFPR, 2001d).
\end{abstract}

Em 2002, o Departamento consegue a liberação de duas vagas para professores adjuntos e também o ingresso de três professores substitutos (UFPR, 2001e; UFPR, 2002a). Enquanto há falta no quadro docente, as turmas e disciplinas são divididas e alternadas entre os professores que se encontram disponíveis, observando, sempre, a área de competência de cada um.

Outra conquista foi a disponibilidade concedida de uma secretária para o departamento, relatada na ata de 11 de abril de 2002. De acordo com o documento, havia a necessidade de uma secretária efetiva desde a criação do DETUR, em abril de 2000. Mas até aquela data o cargo estava sendo atendido pelos bolsistas seniores, sem gratificação para tanto ou para o Chefe do Departamento (UFPR, 2002b). 
Por fim, ainda no ano de 2002, o Curso e o Departamento de Turismo são transferidos do Prédio Histórico para o campus da Reitoria. De acordo com a ata de 8 de agosto de 2002, a Pró-Reitoria de Administração informava que até o dia 19 de agosto deveriam ser terminados os trabalhos de reforma do Edifício Pedro II, estando então pronto para a efetivação da mudança (UFPR, 2002c). Com essa mudança de endereço, o Curso e o Departamento de Turismo passam a usufruir de espaço específico para o desenvolvimento de suas atividades.

Esses são alguns dos entraves enfrentados em alguns anos de existência. Os depoimentos aqui inseridos demonstram o olhar de pessoas que vivenciaram e vivenciam o ensino de turismo no Brasil e especificamente no curso de bacharelado em Turismo da Universidade Federal do Paraná. Assim, ao mesmo tempo percebem mudanças ocorridas ao longo de mais de trinta anos e as suas contribuições, como cita o professor Miguel Bahl:

Bom a gente tem mais 800 bacharéis formados, [...] toda a nossa tradição [...] vários profissionais hoje atuando no mercado, egressos daqui. $\mathrm{Na}$ verdade o nosso curso foi, digamos, o provedor de vários outros cursos, quando houve o boom da criação de cursos de turismo, basicamente o corpo docente dos demais cursos era oriundo daqui.

Esse processo de evolução da construção do conhecimento não ficou restrito apenas aos alunos e aos bancos escolares. Os projetos e programas de extensão vinculados ao curso de Turismo compartilham conhecimento e experiência com a comunidade. Atualmente são vários projetos de extensão e de pesquisa que podem ser citados como referência (alguns encerrados e outros em execução), também existindo a Trilhas Empresa Júnior, como entidade fundada espontaneamente pelos alunos e de apoio ao Curso, tendo recebido o apoio e o incentivo dos professores para a sua criação, além da considerável inserção dos alunos e professores na comunidade científica do turismo no Brasil e no exterior. Além da Trilhas existe o Centro Acadêmico de Turismo - CAT, e que não pode deixar de ser mencionado, pois é o órgão de representação estudantil o qual sempre foi estimulado pelos professores a se manifestar através de representantes nas reuniões de colegiado do Curso e nas plenárias do DETUR.

$\mathrm{Na}$ ata de 20 de fevereiro de 2003, por exemplo, é citada a criação de um dos projetos vinculados ao Curso: o "SerrAção", como segue: 
A professora Laura apresenta à plenária o Projeto de Extensão Universitária "SerrAção - Sensibilização e Conscientização da Comunidade de Piraquara/PR em relação ao Turismo", a ser desenvolvido por alunos do Curso, sob a coordenação da professora Laura Alice Rinaldi Camargo e vicecoordenação da professora Deise Maria Fernandes Bezerra (UFPR, 2003a).

Esse mesmo projeto teve uma expressiva repercussão entre os alunos e é novamente mencionado na ata de 13 de novembro de 2003, onde é citado que o "SerrAção" foi um dos três projetos, entre todos da UFPR, a ser selecionado para participar do Evento Sul-brasileiro de Extensão (UFPR, 2003d).

Assim, em se tratando das contribuições do curso para a sociedade, há que se observar ainda a capacidade de gerar desenvolvimento que a atividade turística oferece para as localidades onde ocorre. Ao longo de suas décadas, o curso atuou junto à comunidade por meio da extensão com projetos como o Serração, Educazer e AGETUR, dentre outros.

A AGETUR, criada há mais de 25 anos, inicialmente com a intenção de ser uma agência de viagem experimental, sofreu transformações e se consolidou como um amplo programa de extensão. Atualmente ela oferece projetos de caminhada na natureza, entretenimento para a terceira idade, visitas guiadas pelos campi da Universidade, dentre outros. Há que se destacar a pesquisa desenvolvida no curso especialmente por meio da iniciação científica e por meio de projetos de professores vinculados a programas de pós-graduação stricto-sensu. Estes produzem conhecimento em diversas áreas ligadas ao turismo como roteiros, cultura, marketing, competitividade, tecnologia da informação, alimentos e bebidas e ética. Outra contribuição do curso diz respeito à realização há mais de 18 anos da SEPATUR (Semana Paranaense de Turismo), anteriormente denominada Encontro Paranaense de Turismo - ENPATUR que já havia sido realizada por oito vezes. Neste evento anual, com a participação de pessoas de diversas organizações nacionais, é possível uma aproximação entre as ideias do mercado e da academia. Assim, por meio deste ambiente privilegiado de construção do conhecimento, ao reunir estudantes, professores, bacharéis e profissionais do turismo, propostas e análises sobre o turismo são apresentadas, possibilitando uma orientação técnica e efetiva para o desenvolvimento do setor (UFPR, 2012).

Somados aos programas e projetos dentro do âmbito acadêmico, os professores desenvolveram, ainda, parcerias com instituições públicas, privadas e paraestatais. $\mathrm{O}$ documento que corrobora com tal afirmativa é a ata de 22 de maio de 2003, em que: 
O professor Gândara informa que esteve, juntamente com a professora Laura, participando hoje de reunião no SENAC, em que ficou acertada a continuidade da parceria de trabalho entre a AGETUR e aquela entidade, mas sempre com abertura para todas as instituições que queiram participar. A intenção é, ainda, desenvolver em parceria um polo de excelência para formação de recursos humanos em turismo (UFPR, 2003b).

As contribuições também podem ser possíveis por meio de conversações, acordos, e até mesmo pela conscientização da comunidade e de autoridades envolvidas sobre a importância do conhecimento, e do turismo enquanto vetor de desenvolvimento humano. No ano de 2003, a professora Laura Alice Rinaldi Camargo e a professora Maria Henriqueta Sperandio Garcia Gimenes, participaram das reuniões sobre a criação do curso de tecnólogo em turismo no Setor Litoral da UFPR (UFPR, 2003c).

Esses são alguns exemplos de benefícios à população paranaense e brasileira, decorrente de um posicionamento pró-ativo por parte dos docentes, técnicos administrativos e acadêmicos do Curso e do Departamento de Turismo.

O professor José Manoel Gonçalves Gândara, ao discorrer sobre o desenvolvimento do curso expõe que:

\begin{abstract}
Hoje nós temos um curso totalmente diferente, para você ter uma ideia quando eu estudei, nós tínhamos quatro disciplinas de turismo, [...], o curso tinha só três anos naquela época, [...] voltei como professor, eu sai em 88 voltei em 95 [...] O curso já tinha passado por várias mudanças, já tinha mais professores, [...] então nós fizemos ao longo de cinco anos, três ajustes, e que na prática mudaram bastante o curso. O curso passou a ter $30 \%$ da sua carga horária flexível, entre optativas e atividades acadêmicas complementares, ou seja, que o aluno pode escolher. O curso passou a ter um foco não só em planejamento e organização do turismo, mas também se buscou dar um foco em gestão do turismo [...] então isso permitiu este desenvolvimento, hoje é um curso totalmente diferente do curso que eu fiz.
\end{abstract}

Em relação à inserção dos egressos do curso no mercado e na academia, o professor José Manoel Gonçalves Gândara salientou que são profissionais que possuem atuações em turismo junto ao setor público, à iniciativa privada, ao planejamento e gestão da atividade, à formação e qualificação e a disponibilidade de formadores. Assim, percebe-se que são variadas as áreas, que contam com profissionais egressos do curso e que têm suas contribuições voltadas para a sociedade.

O professor Eduardo Manoel Marques Pereira, o primeiro profissional de turismo a dar aulas no curso, comentou sobre o desenvolvimento do turismo no Brasil e a contribuição do curso neste processo: 
[...] a partir do desenvolvimento de congressos diversos com a nossa participação que eu vou te dizer que não foi fraca não [...] Então a partir de trabalhos nossos, das nossas participações que sempre foram muito positivas [...] este é o mínimo que a gente pode, é repassar algo daquilo que a gente pretende universalizar, entende? E eternizar e transformar efetivamente o Brasil [...] os maiores trunfos que o Brasil tem [...], é esse nosso potencial turístico, que permanece um potencial, porque ainda, apesar de tudo, nós não conseguimos decolar e ainda não somos um país turístico na dimensão como nós conhecemos.

Assim, o curso de turismo da UFPR vem, ao longo de suas décadas de atuação, promovendo mudanças em seu currículo, conteúdos, projetos de extensão e pesquisa, visitas técnicas e laboratórios visando se aproximar cada vez mais das necessidades dos profissionais e da atividade ainda em desenvolvimento no Brasil. Neste sentido, cabe destacar a percepção do egresso do curso, Paulo Alexandre Monteiro, que atua na área de lazer e recreação em hotéis e resorts brasileiros. Ele comentou sobre o papel da formação acadêmica em turismo:

[...] o turismo funciona como parâmetro de desenvolvimento em vários países, [...] mas a partir do momento que uma atividade, digamos, comercial é também tratada de uma forma acadêmica ela pode estar funcionando também na contribuição da transformação social que afeta a sociedade, [...] o profissionalismo do turismo aqui é muito devido aos profissionais de turismo que se formaram em universidades, uma delas é a Universidade Federal do Paraná, muitos dos casos na atuação turística não necessitam de uma formação acadêmica, apenas a formação técnica já estaria suficiente, mas acredito que as ideias mais criativas, a busca de soluções realmente parte destas pessoas que tiveram a oportunidade de fazer um curso de turismo, então elas têm uma visão mais global do que o turismo implica na sociedade.

Portanto é possível destacar a importância da academia bem como o papel do curso de bacharelado em turismo da UFPR na formação de profissionais e desta forma no desenvolvimento do turismo, atividade recente no Brasil, mas que demonstra grande capacidade de gerar desenvolvimento.

Assim, a discussão que permeia a questão acadêmico/técnico da formação em turismo, se faz também presente no cotidiano do curso de bacharelado em turismo da Universidade Federal do Paraná. A sua dinâmica é marcada por ajustes e readequações curriculares, bem como a proposta de maior flexibilidade e possibilidade de escolha para os alunos em relação às disciplinas. Esta realidade é ressaltada pelo egresso Augusto José Waszczynskyj Antunes das Neves ao analisar o ensino de turismo no curso de bacharelado da UFPR: 
[...] apresentar disciplinas optativas de acordo com as necessidades de mercado [...], o relacionamento entre docentes e discentes, proximidade que possui com empregadores [...] [facilitam] na contratação de alunos, mesmo ainda durante a capacitação acadêmica.

Finalmente, é fundamental destacar a função da universidade pública e especialmente do curso de bacharelado em Turismo UFPR enquanto espaços de educação que apóiam o desenvolvimento do educando, contemplando qualificação para o trabalho, mas também a formação humana e para o exercício da cidadania, como exposto pela egressa Marília de Carvalho Rovai:

\begin{abstract}
No curso encontrei todo amparo estudantil necessário para seguir em frente e com a contribuição da Universidade, eu tinha onde morar, o que comer e como me sustentar aqui. Por isso considero minha ligação com o Curso intrínseca, um sentimento de eterna gratidão pelas oportunidades a mim oferecidas, além da forte participação em minha formação acadêmica e também [...] na minha formação de um ser humano melhor, com plenas noções de ética, responsabilidade social, sustentabilidade.
\end{abstract}

Assim, na perspectiva de observar os desafios dos profissionais de Turismo no século XXI e contrapondo estes ao bacharelado em turismo UFPR podem-se levantar aspectos que são considerados relevantes por estudiosos do turismo sob a ótica da atuação profissional. Ao mesmo tempo é notório que o curso de turismo constrói conhecimentos que contemplam esta formação profissional, mas a ultrapassam visando à formação de um ser humano integral.

\title{
6 CONSIDERAÇÕES FINAIS
}

Dessa maneira, pautado no caráter sistêmico do turismo e nos aspectos relacionados à oferta do curso de bacharelado em Turismo, foi realizada uma análise sócio-histórica do ensino de bacharelado em turismo na UFPR. Assim foi possível compreender que os aspectos históricos que envolvem o ensino de turismo são em grande parte fruto da relação entre academia e sociedade na referida área. A discussão proposta neste artigo intencionou aproximar a realidade do ensino de turismo aos desafios do mercado turístico no século XXI, tendo como estudo de caso o curso de bacharelado em Turismo da Universidade Federal do Paraná.

Primeiramente, foi possível observar que o turismo enquanto atividade recente 
tem em sua estrutura de ensino a discussão constante envolvendo a relação mercado e academia. Esta questão também permeia o cotidiano do curso de Turismo da UFPR. Neste sentido, no curso de bacharelado em Turismo da UFPR diversas mudanças resultaram em uma matriz direcionada para o planejamento e gestão das principais áreas de abrangência do turismo.

Ficou evidenciado também que as configurações assumidas pelo curso ao longo das décadas no que diz respeito ao ensino, à pesquisa e à extensão mantêm relação com as transformações da atividade e principalmente com as áreas de atuação e interesse dos profissionais que o compuseram. A contribuição do curso de bacharelado em turismo da UFPR se faz presente por meio de centenas de egressos, diversos projetos vinculados à sociedade e pesquisas as quais geram novos conhecimentos na área do turismo. Assim, a partir de uma percepção atenta ao mercado, crítica em relação à realidade sociocultural, visando uma formação integral, o curso alcança o seu reconhecimento.

Diante do exposto fica evidente que a pesquisa, sistematização e contextualização dos registros histórico-sociais produzidos na trajetória do ensino nesta área possibilitam identificar a evolução do processo da formação dos profissionais. Alcança-se ainda a redução das falhas (em função daquelas já cometidas), valorização histórica do curso, entendimento da atual realidade (em face de seu histórico) e proposições mais adequadas para o futuro da referida área de estudo.

Nesta perspectiva estudos futuros sobre o curso de bacharelado em Turismo da UFPR podem expandir esta pesquisa através de ampliação da análise documental e contemplando outros protagonistas do curso nas entrevistas. Da mesma maneira, novas pesquisas acerca do ensino de turismo, tendo como fonte: teses, livros e outros artigos científicos, podem contribuir ao enfatizarem aspectos como estrutura curricular, corpo docente, trabalhos de conclusão de curso e atividades desempenhadas pelos discentes fora da sala de aula (como estágios e atividades acadêmicas complementares), abordando o histórico destas práticas no ensino de turismo no Brasil bem como em outros países.

\section{REFERÊNCIAS}

ARANHA, M. L. A. História da Educação e da Pedagogia: geral e Brasil. São Paulo: Moderna, 2006. 
ALENCAR, E. Pesquisa em Turismo. Lavras: UFLA, 2007.

BARDIN, L. Análise de Conteúdo. Lisboa: Edições 70, 1977.

BENI, M. C. Análise Estrutural do Turismo. São Paulo: Editora Senac São Paulo, 2001 .

BENI, M. C. O profissional de turismo na sociedade pós-industrial. In: GASTAL, S.; BENI, M. C.; CASTROGIOVANnI, A. C. Turismo Investigação e Crítica. São Paulo: Contexto, 2002.

CRESWELL, J. W. Projeto de Pesquisa: métodos qualitativo, quantitativo e misto. Porto Alegre: Artmed, 2007.

FREITAS, M. T. A. A Abordagem Sócio-Histórica como orientadora da pesquisa qualitativa. Cadernos de Pesquisa, São Paulo, n. 116, p. 20-39, jul. 2002.

MARTINS, A. C. P. Ensino superior no Brasil: da descoberta aos dias atuais Acta Cirúrgica Brasileira, São Paulo, v. 17, supl. 3, p. 4-6, 2002.

MATIAS, M. Formação Profissional em Turismo no Brasil no Início do Século XXI. In: TRIGO, L. G. G. Análises Regionais e Globais do Turismo Brasileiro. São Paulo: Roca, 2005.

MATIAS, M. Disciplinas. In: MORAES, C. C. A.; ALMEIDA, I. J.; ALMEIDA, M. V.; GIARETTA, M. J; MATIAS, M. Padrões de Qualidade para os Cursos de Bacharelado em Turismo. São Paulo: Arké, 2008.

MEDAGLIA, J.; SILVEIRA, C. E. Reflexões sobre a atuação profissional dos turismólogos e o planejamento do turismo: pesquisa com os egressos dos Cursos de Turismo de Curitiba, Paraná, Brasil. Turismo \& Sociedade, Curitiba, v. 3, n. 2, p. 123 146, out. 2010.

MOESCH, M. M. Para além das disciplinas: o desafio do próximo século. In: GASTAL, S. (org.). Turismo: investigação e crítica. São Paulo: Contexto, 2002.

MORAES, C. C. A. Corpo Docente. In: MORAES, C. C. A.; ALMEIDA, I. J.; ALMEIDA, M. V.; GIARETTA, M. J; MATIAS, M. Padrões de Qualidade para os Cursos de Bacharelado em Turismo. São Paulo: Arké, 2008.

NECHAR, M. C. La investigación y epistemologia del turismo: aportes e retos. Revista Hospitalidade, São Paulo, v. 4, n. 2, p. 79-95, jul.-dez. 2007.

PANOSSO NETTO, A.; NOGUERO, F. T.; JÄGER, M. Por uma Visão Crítica nos Estudos Turísticos. Revista Turismo em Análise, São Paulo, v. 22, n. 3, p. 539-560, dez. 2011. 
SCHLÜTER, R. G. Desenvolvimento do turismo: as perspectivas na América Latina. In: THEOBALD, W. F. Turismo Global. São Paulo: SENAC São Paulo, 2002.

SOGAYAR, R. L.; REJOWSKI, M. Ensino Superior em Turismo em Busca de Novos Paradigmas Educacionais: problemas, desafios e forças de pressão. Revista Turismo Visão e Ação, Balneário Camboriú, v. 13, n. 3, p. 282-298, set-dez 2011.

TOMAZONI, E. L. Educação Profissional em Turismo. Cria-se Mercado pela Formação? Revista Turismo em Análise, São Paulo, v. 18, n. 2, p. 197-219, 2007.

TRIVINOS, A. N. S. Introdução à Pesquisa em Ciências Sociais: a pesquisa qualitativa em educação. São Paulo: Atlas, 1987.

Universidade Federal do Paraná (UFPR). Disponível em: <http://www.ufpr.br/portalufpr/historico-2>. Acesso em 21/12/ 2011.

Universidade Federal do Paraná (UFPR). Disponível em: <http://www.turismo.ufpr.br/sepatur>. Acesso em 23/9/ 2012.

Universidade Federal do Paraná (UFPR). Departamento de Turismo. Ata da reunião realizada no dia 6 de março de 2001 .

Universidade Federal do Paraná (UFPR). Departamento de Turismo. Ata da reunião realizada no dia 13 de março de $2001 b$.

Universidade Federal do Paraná (UFPR). Departamento de Turismo. Ata da reunião realizada no dia 5 de abril de 2001c.

Universidade Federal do Paraná (UFPR). Departamento de Turismo. Ata da reunião realizada no dia 23 de outubro de $2001 d$.

Universidade Federal do Paraná (UFPR). Departamento de Turismo. Ata da reunião realizada no dia 17 de dezembro de 2001 .

Universidade Federal do Paraná (UFPR). Departamento de Turismo. Ata da reunião realizada no dia 6 de março de 2002 a.

Universidade Federal do Paraná (UFPR). Departamento de Turismo. Ata da reunião realizada no dia 11 de abril de $2002 b$.

Universidade Federal do Paraná (UFPR). Departamento de Turismo. Ata da reunião realizada no dia 8 de agosto de 2002 c.

Universidade Federal do Paraná (UFPR). Departamento de Turismo. Ata da reunião realizada no dia 20 de fevereiro de 2003a.

Universidade Federal do Paraná (UFPR). Departamento de Turismo. Ata da reunião realizada no dia 22 de maio de $2003 b$. 
Universidade Federal do Paraná (UFPR). Departamento de Turismo. Ata da reunião realizada no dia 10 de julho de $2003 c$.

Universidade Federal do Paraná (UFPR). Departamento de Turismo. Ata da reunião realizada no dia 13 de novembro de $2003 d$.

Recebido em: 29-03-2012.

Aprovado em: 29-04-2012. 